\title{
Empirical therapy or precision medicine for kidney stone formers in the '-omics' era?
}

\author{
Giovanni Gambaro ${ }^{1}$ (1)
}

Received: 12 November 2018 / Accepted: 26 November 2018 / Published online: 29 November 2018

c) Springer-Verlag GmbH Germany, part of Springer Nature 2018

Identifying specific molecules and cellular pathways involved in the pathogenesis of a given patient's disease is the key to developing personalized drugs addressing such targets. Patient genotyping is often needed to discover these specific molecular targets. Recent technological advances have been making it easier, quicker, and cheaper to genotype individual patients, letting us glimpse the feasibility of a medicine tailored to every single patient.

Is this what lies just around the corner for kidney stone patients too? I think not. The stone disease commonly seen in the general population (which has a huge prevalence, $8-10 \%$ ) is a complex condition with polygenic predisposing factors that, when triggered by environmental and nutritional conditions, and lifestyle, gives rise to renal stones. This is elegantly discussed by Palsson et al. in the present issue [1]. While we generally assume that the genes involved deal with the renal and systemic handling of minerals, the Mayo Clinic group has also produced data to suggest that the picture may well be more complicated: it appears that some of the genes involved in the pathogenesis of stone formation might modulate eating habits [2]. Be that as it may, the genes predisposing to the common nephrolithiasis probably have a small, or even a very small role, so we should reasonably expect none of the corresponding proteins, receptors and/ or enzymes to be useful targets for personalized preventive treatments.

That said, there are at least 30 different genes capable of causing Mendelian forms of nephrolithiasis [3], but such conditions are rare, and some exceedingly so. All in all, probably, less than $2 \%$ of the general population of stone formers have monogenic forms of the disease. Recent contributions from Hildebrandt's group [4-6] give the impression

Giovanni Gambaro

giovanni.gambaro@univr.it

1 Renal Unit, Division of Nephrology and Dialysis, Department of Medicine, University of Verona, Ospedale Maggiore, Piazzale A. Stefani 1, 37126 Verona, Italy that such monogenic stone diseases are quite frequent, however, and would account for 15-34\% of cases, depending on the case populations investigated. While I think that their conclusion is biased, I see their studies as an excellent demonstration of the fact that, to perform well, powerful modern genetic technologies need to be applied to highly selected populations of stone formers. Even so, $66-85 \%$ of the individuals among the carefully selected cases in the abovementioned studies [4-6] revealed no mutations. This finding should prompt us to improve our clinical skills in pinpointing which stone-forming patients are most likely to have a monogenic disorder, and then running molecular diagnostics only on them. This is extremely important, even though we still do not have drugs capable of correcting specific defects, because these disorders carry a high risk of chronic and endstage kidney disease, and systemic morbidities. Identifying them could help ameliorate a dismal prognosis.

Better clinical skills would have a further advantage: biochemical tests are often simple and inexpensive, and can diagnose inherited conditions more rapidly than genetic tests. This is the case, for instance, of low serum phosphate levels and high phosphate tubular maxima (TmP), or very low serum uric acid and high uric acid fractional excretion (FE), which can diagnose tubular defects in the handling of phosphate and uric acid, respectively. The same can be said of cystinuria. It was frustrating to read in a previously quoted paper [4] that seemingly, the first time the diagnosis of cystinuria was done was in the occasion of the study and this happened in a huge 22 subjects of the 40 patients considered.

Improving our clinical skills would, therefore, save money and time spent on the diagnostic work-up of stone formers.

In a way, the empirical approach to managing kidney stone patients-very nicely presented by Goldfarb and co. in this issue [7]—complements the strategy based on molecular testing for all stone formers straight away, without any refinements of the clinical and biochemical 
diagnosis. Goldfarb [7] is right in saying that we generally treat the majority of calcium stone formers with the same drugs, the same dietary restrictions, and the same lifestyle recommendations. This is due mainly to the fact that our therapeutic armamentarium is very limited and oldfashioned. This means that, for the purposes of preventing their stones from recurring, we do not need to know much about our patients' clinical and biochemical phenotype. I struggle with this nihilistic approach, however, because it carries a very high risk of making us lose the chance to properly diagnose and treat that minority of patients with nephrolithiasis (including the inherited forms, and all other secondary forms) who could benefit from specific and/or ancillary treatments (e.g., parathyroidectomy or treatments for slowing the progression of chronic kidney disease, respectively). Take the case of cystinuria, for example. It is easy to diagnose from a simple urine test, or by analyzing a stone's composition, but-as far as we know-it was never even suspected in stone formers, whose siblings were cystinuric [8], as confirmed by a recent UK survey [9]. That is incredible! How was it possible? ... I think this a good example of the risks of the empirical approach.

I am sure that, in good hands, an empirical management of kidney stone formers is safe. I am equally confident that, under watchful eyes, genetic testing in stone formers is a potent tool. What worries me is the dissemination of the idea that: (a) there is no need to investigate stone formers too much, because their treatment is more or less the same anyway or (b) we can take a short-cut to the diagnosis by performing genetic tests on all stone formers. I fear that all this could lead either to us failing to recognize cases that need more than the standard, classic treatment, or to a pointless rise in the costs of diagnostics and an inflation of dubious genetic diagnoses (not all gene variants are disease-causing mutations).

The genetic causes of nephrolithiasis are presented in this issue of Urolithiasis. Many advances in our understanding of the etiology and pathogenesis of nephrolithiasis have been made in the last few years, with genetic investigations contributing a great deal. Now, we have a more detailed knowledge of the abnormalities in the proximal and distal nephron that cause stone formation and of their frequently monogenic origin. The articles by Oliveira et al. [10] and Fuster et al. [11] cover these topics, together with the comprehensive overview by Vezzoli et al. on the relationship between kidney stone disease and the calcium-sensing receptor [12]. For many disorders, our more in-depth knowledge has yet to generate targeted therapies, but the two articles on the primary hyperoxalurias $[13,14]$ paint an encouraging picture for the diagnosis and treatment of these very rare, severe disorders. The same applies to the issue of cystinuria, which holds a promise brilliantly illustrated by Sahota et al. [15].
Hopefully, this dedicated issue of the Journal will improve stone doctors' awareness concerning inherited forms of nephrolithiasis and their ability to diagnose them. These disorders are rare, but recognizing them could improve the chances of the patients concerned, thanks possibly to more personalized treatments, more often to a stricter follow-up to prevent renal and systemic complications, and partly to a greater likelihood of an earlier, living donor transplantation.

\section{Compliance with ethical standards}

Conflict of interest Authors have no conflict of interest.

\section{References}

1. Palsson R et al (2019) Genetics of common complex kidney stone disease: insights from genome-wide association studies. Urolithiasis (current issue)

2. Wang X, Lieske JC (2018) Heritable traits that contribute to nephrolithiasis. Urolithiasis. https://doi.org/10.1007/s0024 0-018-1095-1

3. Hill F, Sayer JA (2018) Precision medicine in renal stone-formers. Urolithiasis. https://doi.org/10.1007/s00240-018-1091-5

4. Halbritter J, Baum M, Hynes AM, Rice SJ, Thwaites DT, Gucev ZS, Fisher B, Spaneas L, Porath JD, Braun DA, Wassner AJ, Nelson CP, Tasic V, Sayer JA, Hildebrandt F (2015) Fourteen monogenic genes account for $15 \%$ of nephrolithiasis/nephrocalcinosis. J Am Soc Nephrol 26:543-551

5. Braun DA, Lawson JA, Gee HY, Halbritter J, Shril S, Tan W, Stein D, Wassner AJ, Ferguson MA, Gucev Z, Fisher B, Spaneas L, Varner J, Sayer JA, Milosevic D, Baum M, Tasic V, Hildebrandt F (2015) Prevalence of monogenic causes in pediatric patients with nephrolithiasis or nephrocalcinosis. Clin J Am Soc Nephrol 11:664-672

6. Daga A, Majmundar AJ, Braun DA, Gee HY, Lawson JA, Shril S, Jobst-Schwan T, Vivante A, Schapiro D, Tan W, Warejko JK, Widmeier E, Nelson CP, Fathy HM, Gucev Z, Soliman NA, Hashmi S, Halbritter J, Halty M, Kari JA, El-Desoky S, Ferguson MA, Somers MJG, Traum AZ, Stein DR, Daouk GH, Rodig NM, Katz A, Hanna C, Schwaderer AL, Sayer JA, Wassner AJ, Mane S, Lifton RP, Milosevic D, Tasic V, Baum MA, Hildebrandt F (2018) Whole exome sequencing frequently detects a monogenic cause in early onset nephrolithiasis and nephrocalcinosis. Kidney Int 93:204-213

7. Goldfarb DS (2019) Empiric therapy of kidney stones. Urolithiasis (current issue)

8. Ferraro PM, D'Addessi A, Gambaro G (2013) When to suspect a genetic disorder in a patient with renal stones, and why. Nephrol Dial Transplant 28:811-820

9. Rhodes HL, Yarram-Smith L, Rice SJ, Tabaksert A, Edwards N, Hartley A, Woodward MN, Smithson SL, Tomson C, Welsh GI, Williams M, Thwaites DT, Sayer JA, Coward RJ (2015) Clinical and genetic analysis of patients with cystinuria in the United Kingdom. Clin J Am Soc Nephrol 10:1235-1245

10. Oliveira B et al (2019) Inherited proximal tubular disorders and nephrolithiasis. Urolithiasis (current issue)

11. Faller N, Dhayat NA, Fuster DG (2018) Nephrolithiasis secondary to inherited defects in the thick ascending loop of henle and connecting tubules. Urolithiasis. https://doi.org/10.1007/s0024 0-018-1097-z 
12. Vezzoli G, Macrina L, Magni G, Arcidiacono T (2018) Calciumsensing receptor: evidence and hypothesis for its role in nephrolithiasis. Urolithiasis. https://doi.org/10.1007/s00240-018-1096-0

13. Dindo M, Conter C, Oppici E, Ceccarelli V, Marinucci L, Cellini B (2018) Molecular basis of primary hyperoxaluria: clues to innovative treatments. Urolithiasis. https://doi.org/10.1007/s0024 0-018-1089-Z
14. Sas DJ et al (2019) Recent advances in the identification and management of inherited hyperoxalurias. Urolithiasis. https:// doi.org/10.1007/s00240-018-1093-3

15. Sahota A et al (2019) Cystinuria: genetic aspects, mouse models, and a new approach to therapy. Urolithiasis. https://doi. org/10.1007/s00240-018-1101-7 